\title{
57 EFFECT OF RUNNING AND SWIMMING ACTIVITIES ON SELECTED CARDIAC RISK FACTORS AMONG MIDDLE AGED MEN
}

Ajay Kumar Koorma, ${ }^{1}$ S Chidambara Raja2 ${ }^{1}$ Department of Physical Education, SN

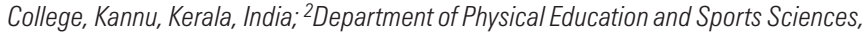
Annamalai University, Chidambaram, Tamil Nadu, India

10.1136/bjsm.2010.078725.57

The purpose of the study was to find out the effect of running and swimming activities on coronary heart disease risk factors. Thirty male teachers aged between 35 and 40 years who knew swimming were selected for the study. They were divided into three equal groups, each group consisted of 10 subjects in which group I underwent running activity and group II underwent swimming activity, 3 days per week for 12 weeks, and group III acted as control, who did not participate in any training. The subjects were tested on selected criterion variables such as total cholesterol, high-density lipoprotein, systolic and diastolic blood pressure prior to and immediately after the training period. The analysis of covariance was used to find out the significant difference if any, between the experimental groups and control group on selected criterion variables separately. The selected criterion variables such as high-density lipoprotein were improved significantly for both the training groups when compared with the control group and the systolic blood pressure was reduced significantly only for running activity group and swimming activity group. The diastolic blood pressure and total cholesterol were not changed significantly for both the training groups. 